\title{
CUMULATIVE EFFECTS OF ULTRAVIOLET RADIATION AND PHOTOSYNTHEICALLY ACTIVE RADIATION ON PHYCOBILIPROTEINS OF A HOT-SPRING CYANOBACATRIUM NOSTOC SP. STRAIN HKAR-2
}

\author{
Vinod K. Kannaujiya ${ }^{1,2}$, Akhlaqur Rahman ${ }^{1}$, Adinath ${ }^{1}$, Arun S. Sonker ${ }^{2}$, Jainendra Pathak ${ }^{2}$, Rajneesh ${ }^{2}$, Shanthy \\ Sundaram $^{1 *}$ and Rajeshwar P. Sinha ${ }^{2 * *}$ \\ ${ }^{1}$ Centre of Biotechnology, Nehru Science Centre, University of Allahabad, Allahabad-211002, India \\ ${ }^{2}$ Laboratory of Photobiology and Molecular Microbiology, Centre of Advanced Study in Botany, Institute of Science, Banaras Hindu University, Varanasi- \\ 221005, India \\ *Corresponding author's email: shanthy.cbt@gmail.com \\ **Corresponding author's emails: r.p.sinha@gmx.net; rpsinhabhu@gmail.com
}

\begin{abstract}
Cyanobacteria are cosmopolitan in distribution and have adapted to diverse habitats. Adaptation of cyanobacteria is one of the key factors to withstand harsh environmental conditions. We have investigated the effects of photosynthetically active radiation (PAR; $400-700 \mathrm{~nm}$ ), ultraviolet-B (UV-B; 280-315 nm) radiation and PAR+UV-B radiations on phycobiliproteins (PBPs) of a hot-spring cyanobacterium Nostoc sp. HKAR-2. There was a continuous induction of both phycoerythrin (PE) and phycocyanin (PC) after exposure of PAR up to 300 min. However, there was an induction in the synthesis of both PE and PC up to $240 \mathrm{~min}$ exposure of UV-B and PAR+UV-B radiations. Further exposure showed decline in the synthesis due to rapid uncoupling, bleaching and degradation of PBPs. Similarly, emission fluorescence also showed an induction with a shift towards longer wavelengths after 240 min of UV-B and PAR+UV-B exposure. These results indicate that short duration of UV radiation may promote the synthesis of PBPs that can be utilized in various biotechnological and biomedical applications.
\end{abstract}

Keywords: Cyanobacteria; Fluorescence; Phycocyanin; Phycoerythrin; UV radiation.

\section{Introduction}

Cyanobacteria are the most ancient and dominant group of Gram-negative photosynthetic prokaryotes having cosmopolitan distribution from moderate to extreme habitats (Fischer, 2008; Ballaré et al., 2011). Cyanobacteria are the most abundant nitrogen-fixing microorganisms in the rice paddy fields. They play a significant role in improving soil fertility, maintaining the nitrogen cycle and energy dynamics in ecosystem (Roger and Kulasooriya, 1980; Sinha and Häder, 1996; Sinha et al., 2001; Stock et al., 2014). Moreover, cyanobacteria are also considered as model organisms in biotechnological and space research due to their survivability in extreme abiotic and biotic stressed habitats (Olsson-Francis et al., 2013; Rastogi et al., 2014). Cyanobacteria are well characterized for their various applications in several fields of biotechnology and biomedical sciences (Richa et al., 2011; Kannaujiya and Sinha, 2016a).

Solar spectrum is the primary source of photonic energy for storing carbon products in photosynthetic organisms on the Earth's surface. Solar spectrum is physically divided into three major groups such as infrared (IR; $780 \mathrm{~nm}$ ), photosynthetically active radiation (PAR; 400-700 nm), and ultraviolet radiation (UVR; 100-400 nm) that reaches on the Earth's surface. UVR can be divided into three spectral regions (based on wavelengths and energy) such as UV-A (315 - $400 \mathrm{~nm})$, UV-B (280 - $315 \mathrm{~nm})$, and UV-C $(100-280 \mathrm{~nm})$. The lower wavelength and highly energetic $\mathrm{UV}-\mathrm{C}$ radiation is extremely harmful, fortunately it never reaches to the Earth's surface due to complete absorption by ozone (Madronich et al., 1998, Kannaujiya et al., 2014; Kannaujiya and Sinha, 2015). The fraction of solar radiation consists of reduced energy UV-A (95\%) that reaches to the Earth's surface (Santos et al., 2013). About 5\% UV-B radiation which is not completely absorbed by stratospheric ozone layer reaches to the Earth's surface and is harmful to all living organisms (Polo et al., 2014).

It has been reported that cyanobacterial light harvesting proteins absorb > $99 \%$ total solar radiation (Lao and Glazer, 1996), but < $1 \%$ UV-B radiation is enough to cause several deleterious effects on living organisms. Phycobilisomes (PBSs) constitute $50 \%$ of the total soluble proteins in 
cyanobacteria. It has been characterized into three groups such as phycoerythrin (PE), phycocyanin (PC) and allophycocyanin (APC) with absorbance ranging from 450 to $660 \mathrm{~nm}$ (Grossman et al., 1993; Sinha and Häder, 2003). Structurally, PBSs are arranged in trimeric-hexameric macromolecular assembly (3-7M Da) with colorless linker polypeptides in six to eight rods and a core having two to five cylinders (Adir, 2008) (Fig. 1A, B, C).

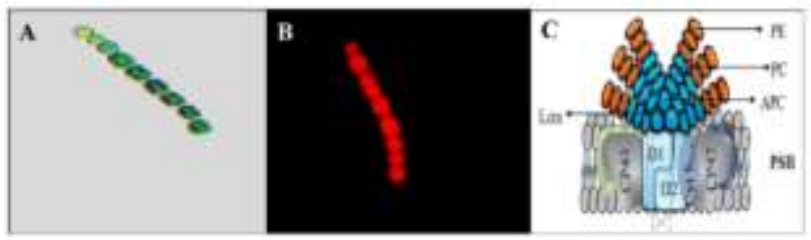

Fig. 1: Microphotograph of Nostos sp. strain HKAR-2 in light microscope (A) and fluorescence microscope (B). Structure of phycobilisome (C).

The monomer unit of each of PBS consists of $\alpha$ and $\beta$ subunits with molecular mass 15-20 kDa and 17-22 kDa respectively (Sinha et al., 1995a; Kannaujiya et al., 2016). In addition to PBS, $15 \%$ non-pigmented linker polypeptides also play distinguished role in the stabilization of complex (Tandeau de Mersac and Cohen-Bazire, 1977). Some cyanobacterial strains have the capability to grow at high temperature in hot springs having highly stable PBS composition (Pumas et al., 2011).

The aim of present investigation was to study the cumulative effects of UV-B and PAR irradiations on PBPs composition of a hot-spring cyanobacterium Nostoc sp. strain HKAR-2. Our results elucidate the spectroscopic and chromophore fluorescence stability of PC and PE. This investigation may provide an insight for the production and utilization of PBPs from cyanobacteria.

\section{Materials and Methods}

\section{Organism and Growth Condition}

The cyanobacterium Nostoc sp. strain HKAR-2 (Rastogi et al., 2012) was isolated from the hot-springs of Bihar, India $\left(25^{\circ} 0{ }^{\prime} 45^{\prime \prime} \mathrm{N} 85^{\circ} 25^{\prime} 7^{\prime \prime} \mathrm{E}\right)$, at $74 \mathrm{~m}$ above sea level. Isolated culture was purified and routinely grown in BG-11 10 medium (Rippka et al., 1979) at $20 \pm 2{ }^{\circ} \mathrm{C}$ and illuminated with day light fluorescent tubes having photon flux density of $94 \mu \mathrm{m}$ $\mathrm{m}^{-2} \mathrm{~s}^{-1}$ at the surface of the vessels with a 14/10 light/dark cycle. The cyanobacterium Nostoc sp. HKAR-2 (FJ939126) was identified by using the standard taxonomic keys as well as by $16 S$ rRNA gene sequencing.

\section{Radiation Conditions}

Cyanobacterial suspension culture was transferred into three sterile Petri dishes $(150 \times 25 \mathrm{~mm})$. Petri dishes were wrapped with 295, $395 \mathrm{~nm}$ cut-off filter foils (Ultraphan, UV Opak Digefra, Munich, Germany) for the effects of PAR, UV-B and PAR+UV-B radiations. Petri dishes were kept on rotary shaker in a self-assembled opaque UV chamber equipped with fluorescent white light (OSRAM L
36 W: 32 Lumilux deluxe warm white and Radium NL 36 W: 26 Universal white, Germany) and UV-B tube (Philips Ultraviolet-B TL $40 \mathrm{~W}: 12$, Holland) at constant temperature $\left(20 \pm 5{ }^{\circ} \mathrm{C}\right)$. The exposure of cyanobacterium was fixed at $\sim 0.7 \mathrm{Wm}^{-2}$ and $55.08 \pm 9.18 \mu \mathrm{m} \mathrm{m}^{-2} \mathrm{~s}^{-1}$ under UV-B irradiation and PAR respectively. The cultures were exposed to UV-B and PAR irradiation for $300 \mathrm{~min}$ and aliquots were withdrawn after 30,60, 120, 180, 240, 300 min of radiation.

\section{Extraction and Purification of Phycobiliproteins}

The extraction and purification of PBPs were done by adopting the method of Sinha et al. (1995a). Suspended aliquots of cyanobacterial culture were washed with $0.75 \mathrm{M}$ potassium phosphate buffer $(\mathrm{pH} 7.5)$ and resuspended in reaction mixture containing $1 \quad \mathrm{mM}$ phenylmethanesulfonylfluoride (PMSF), $10 \%$ (w/v) EDTA, and $5 \%(\mathrm{w} / \mathrm{v})$ sucrose. The separation and purification of PBPs were done by the method as described earlier (Kannaujiya and Sinha, 2016b).

\section{Spectroscopic Measurements}

Absorption spectra of PC (615 nm) and PE (563 nm) were measured by using UV-Vis double beam spectrophotometer (U-2910, 2J1-0012, Hitachi, Tokyo, Japan). Excitation fluorescence spectra of PC and PE were measured by spectrofluorometer (F-2500, Hitachi, Tokyo, Japan) at 615 $\mathrm{nm}$ and $563 \mathrm{~nm}$ respectively. The peak analyses of emission wavelength of PC $(642 \mathrm{~nm})$ and PE $(575 \mathrm{~nm})$ were performed by using the software FL Solution provided by Hitachi corporation. The immobilization of cyanobacterial filaments was done by using $4 \%$ gelling agarose (Reize and Melkonian, 1989) by using the method as described earlier (Sinha et al., 2002). Fluorescence images were taken by using a fluorescence microscope (Nikon Eclipse-E800) after excitation at a wavelength of $550 \mathrm{~nm}$ up to $600 \mathrm{~ms}$.

\section{Statistical Analyses}

All the experiments were repeated thrice with at least three replicates. One-way analyses of variance with multiple comparison modes were applied to evaluate the significance of data $(P \leq 0.05)$. SPSS-20 and Sigma Plot 11 softwares were used for statistical analyses.

\section{Results and Discussion}

\section{Extraction and Purification of PBPs}

Absorption spectrum of the crude extracts (Fig. 2A) showed that the cyanobacterium Nostoc sp. strain HKAR-2 contains mainly PE (Ex.563 nm) and PC (Ex.615 nm) components of the PBPs. The fluorescence emission of purified PC and PE was recorded after excitation at Ex.615 nm and Ex.563 nm respectively. A sharp peak at the emission wavelengths for individual PC (Fig. 2B) and PE (Fig. 2C) was recorded at the wavelength of $\sim 574$ and $\sim 646 \mathrm{~nm}$, respectively. After completion of purification processes the color of $\mathrm{PE}$ appeared as pink (Fig. 3A) and that of PC blue (Fig. 3B). Intense color of PBPs is dependent on the high purity ratio. 
Highly purified PBPs are used for making high quality products and therefore there is a tremendous increasing demand for pure PBPs (Kannaujiya and Sinha, 2016b). Purity ratio of around $0.7,3.9$ and $>4.0$ has been considered for making food grade, reactive grade and analytical grade bioproducts respectively (Chaiklahan et al., 2012).
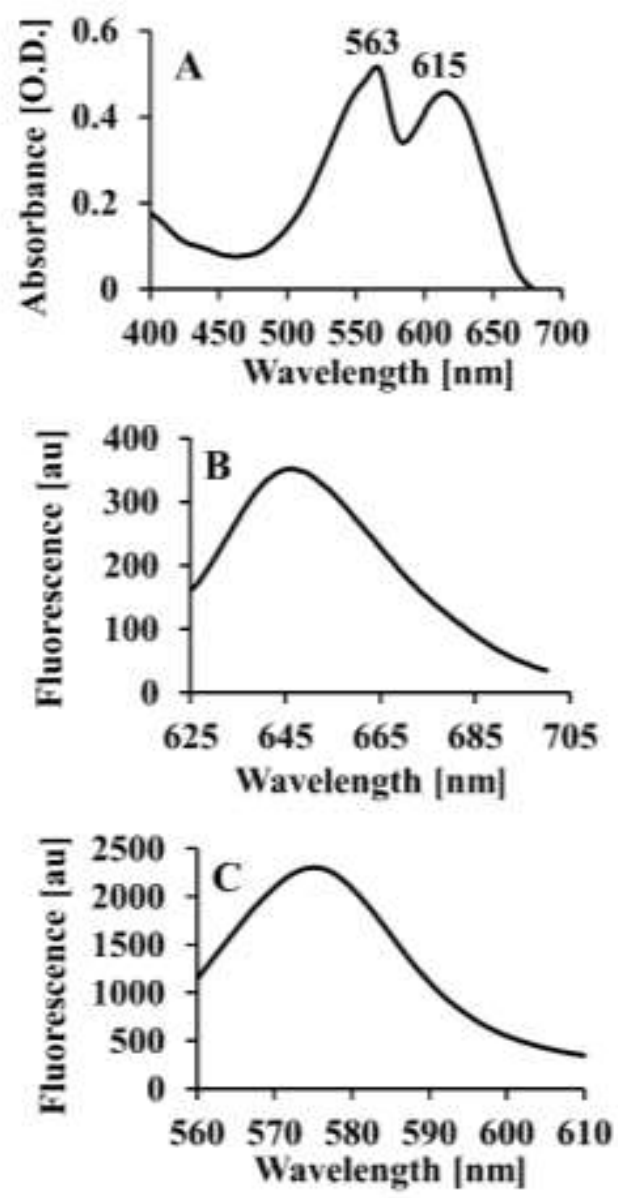

Fig. 2: Absorbance and fluorescence spectra of PC $(615 \mathrm{~nm})$ and PE $(563 \mathrm{~nm})$ of Nostos sp. strain HKAR-2.

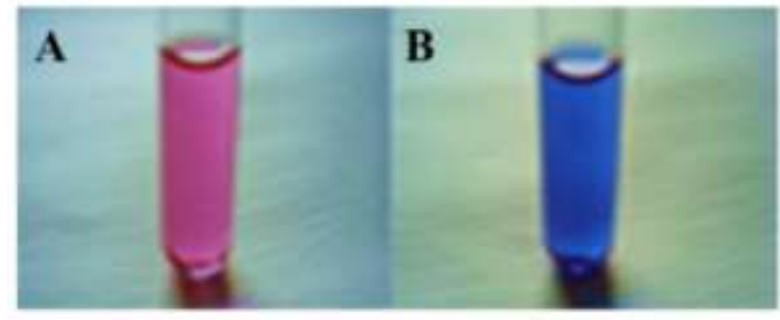

Fig. 3: Purified PE (A) and PC (B).

\section{Spectrophotometric Analyses of PBPs}

Current depletion of ozone layer is the primary cause of elevated UV-B radiation that is potentially harmful to all the living organisms including cyanobacteria (Sinha et al. 1996; Häder and Sinha, 2005; Sinha et al., 2008). It is a well-established fact that longer duration of exposure is more deleterious (Rastogi et al., 2011; Kannaujiya et al., 2014; Häder et al., 2015; Kannaujiya and Sinha 2015, 2016c). To determine the short duration impacts of PAR and UV-B radiations on PBPs, exponentially growing cyanobacterium was exposed to PAR, UV-B and PAR+UV$B$ irradiations up to $300 \mathrm{~min}$. Absorption of PE was continuously increased up to 2.8 fold as compared to control after 300 min exposure of PAR with distinct significant difference $(P<0.05)$. The same absorption was increased up to 2.9 fold $(P<0.05)$ after $240 \mathrm{~min}$ of $U \mathrm{~V}-\mathrm{B}$ radiation. Further exposure with UV-B radiation reduced the absorption of PC. The combination of UV-B and PAR irradiation reduces the amount up to 2.1 fold as compared to control with no significant differences $(\mathrm{P}>0.05)$ (Fig. 4A). Absorption of PE was also continuously increased up to 3.1 fold as compared to control after $300 \mathrm{~min}$ exposure of PAR. In contrast to PAR, absorption of PC was increased up to 3 fold with significant differences $(\mathrm{P}<0.05)$ after 240 min exposure of UV-B radiation and declined after further exposure. The combined effects of UV-B and PAR irradiation was the same as UV-B radiation as compared to control with no significant differences ( $\mathrm{P}>0.05)$ (Fig. 4B). Similar time-dependent photobleaching and destruction of PBPs have been reported in Anabaena sp. and Nostoc carmium (Sinha et al., 1995a), Nostoc sp. (Sinha et al., 1995b) and Aulosira fertilissima (Banerjee et al., 1998). However, short duration and weak exposure may promote induction of PBPs in certain cyanobacteria (Kannaujiya and Sinha, 2016c).
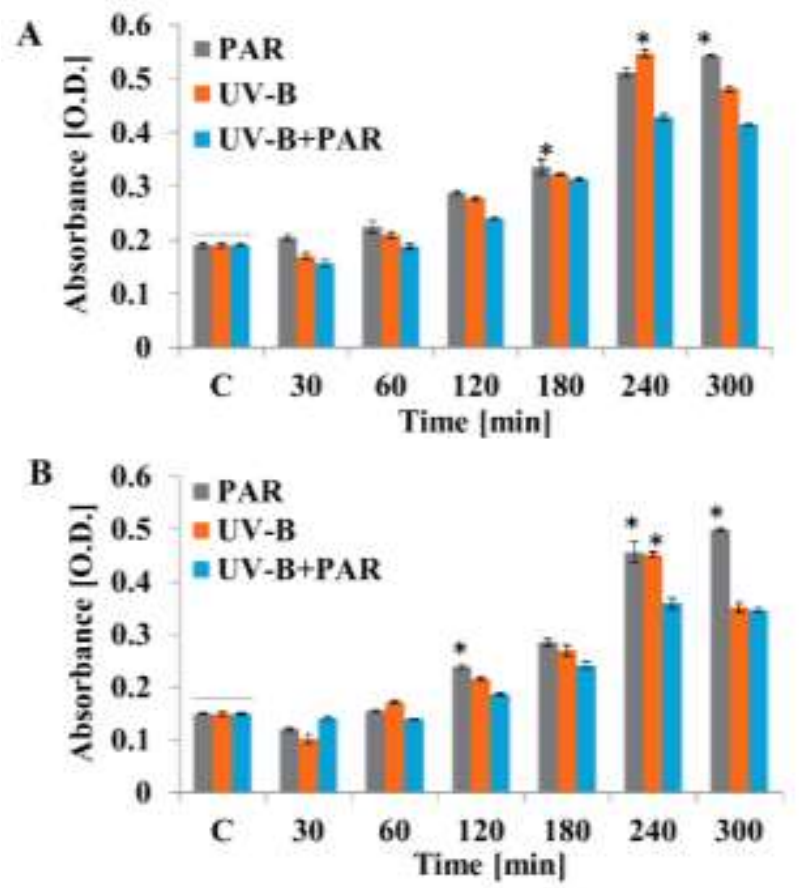

Fig. 4: Absorbance values of $\mathrm{PE}(\mathrm{A})$ and $\mathrm{PC}(\mathrm{B})$ after exposure of PAR, UV-B and PAR+UV-B radiations. Horizontal line over bars indicate no significant differences $(\mathrm{P}>0.05)$. Asterisk marks indicate significant differences $(\mathrm{P}<0.05)$ with the control $(0$ h). The error bar denotes standard deviations of means $(n=3)$. 


\section{Fluorometric Analysis of PBPs}

The fluorescence emission of PE was continuously increased up to 2 fold with no significant differences after $240 \mathrm{~min}$ of exposure to PAR. A slight decline in fluorescence was observed after $300 \mathrm{~min}$. The reduction in fluorescence intensity of PBPs was most probably due to the phenomena of chromophore photobleaching and detachment from rods and core subunits. In contrast to PAR, UV-B radiation induced ( 2.2 fold) the intensity of PBPs after $240 \mathrm{~min}$ of exposure. Further exposure resulted in decline in fluorescence. However, combination of PAR+ UV-B had resulted in slight increase in fluorescence intensity after $300 \mathrm{~min}$ of exposure in comparison to control (Fig. 5A). Similar effects have been observed with emission fluorescence of PC after exposure of PAR and UV-B radiation. Combination of $\mathrm{PAR}+\mathrm{UV}-\mathrm{B}$ resulted in a slight increase in $\mathrm{PC}$ after $300 \mathrm{~min}$ of exposure (Fig. 5B).

\section{Fluorescence Wavelength Shifting}

Both emission fluorescence of PE (574 nm) and PC (646 $\mathrm{nm}$ ) were slightly shifted towards shorter or longer wavelengths as compared to control after exposure of PAR. In contrast to PAR, emission fluorescence of PE had shifted to longer wavelengths from 574-576 after 240 min of UVB exposure. Similarly, a slight change in PE fluorescence was observed after $240 \mathrm{~min}$ of $\mathrm{PAR}+\mathrm{UVB}$ radiation. The emission fluorescence of PC was shifted towards shorter wavelengths after UV-B and PAR+UV-B radiations after 300 min of exposure (Table 1)
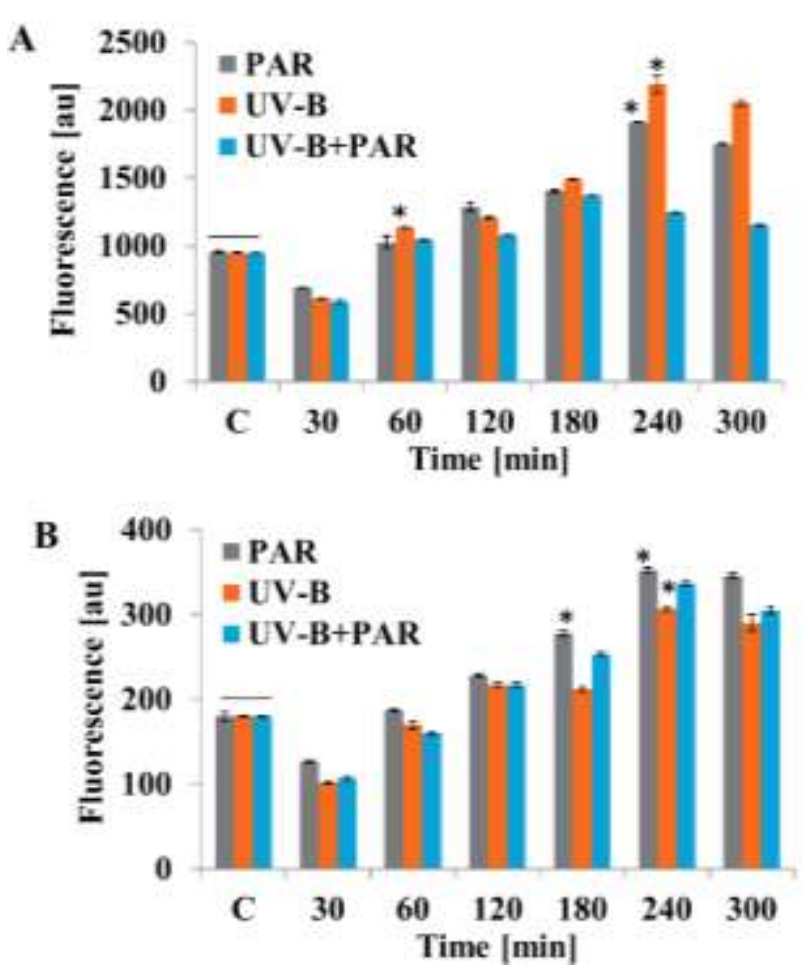

Fig. 5: Fluorescence values of $P E(A)$ and $P C$ (B) after exposure of PAR, UV-B and PAR+UV-B radiations. Horizontal line over bars indicate no significant differences $(\mathrm{P}>0.05)$. Asterisk marks indicate significant differences $(\mathrm{P}<0.05)$ with the control $(0$ h). The error bar denotes standard deviations of means $(n=3)$.

Table 1: Fluorescence emission wavelength shifts in PE and PC of Nostoc sp. HKAR-2 after 300 min of exposure to PAR, UV$\mathrm{B}$ and PAR+UV-B radiations. Em.: Emission; $\mathrm{Em}^{0}$ : Emission at $0 \mathrm{~min}$ of exposure; Em ${ }^{\mathrm{n}}$ : Emission after $\mathrm{n}$ min of exposure.

\begin{tabular}{|l|l|l|l|l|l|l|}
\hline \multirow{2}{*}{$\begin{array}{l}\text { Time } \\
(\text { min })\end{array}$} & $\begin{array}{l}\text { PE- Em. } \\
\left(\mathrm{Em}^{0} \pm \mathrm{Em}^{\mathrm{n}}\right)\end{array}$ & $\begin{array}{l}\text { PC- Em. } \\
\left(\mathrm{Em}^{0} \pm \mathrm{Em}^{\mathrm{n}}\right)\end{array}$ & $\begin{array}{l}\text { PE- Em. } \\
\left(\mathrm{Em}{ }^{0} \pm \mathrm{Em}^{\mathrm{n}}\right)\end{array}$ & $\begin{array}{l}\text { PC- Em. } \\
\left(E m^{0} \pm \mathrm{Em}^{\mathrm{n}}\right)\end{array}$ & $\begin{array}{l}\text { UE- Em. } \\
\left(\mathrm{Em}^{0} \pm \mathrm{Em}^{\mathrm{n}}\right)\end{array}$ & $\begin{array}{l}\text { UC-Em. } \\
\left(\mathrm{Em}^{0} \pm \mathrm{Em}^{\mathrm{n}}\right)\end{array}$ \\
\hline Control & $574(0)$ & $646(0)$ & $574(0)$ & $646(0)$ & $574(0)$ & $646(0)$ \\
\hline 30 & $575(+1)$ & $643(-3)$ & $573(-2)$ & $642(-4)$ & $574(0)$ & $643(-3)$ \\
\hline 60 & $574(0)$ & $643(-3)$ & $574(0)$ & $643(-3)$ & $574(0)$ & $643(-3)$ \\
\hline 120 & $574(0)$ & $645(-1)$ & $575(+1)$ & $644(-2)$ & $575(+1)$ & $644(-2)$ \\
\hline 180 & $574(0)$ & $645(-1)$ & $575(+1)$ & $644(-2)$ & $575(+1)$ & $645(-1)$ \\
\hline 240 & $575(+1)$ & $646(0)$ & $576(+2)$ & $645(-1)$ & $574(0)$ & $646(0)$ \\
\hline 300 & $574(0)$ & $646(0)$ & $568(-6)$ & $639(-7)$ & $570(-3)$ & $640(-6)$ \\
\hline
\end{tabular}




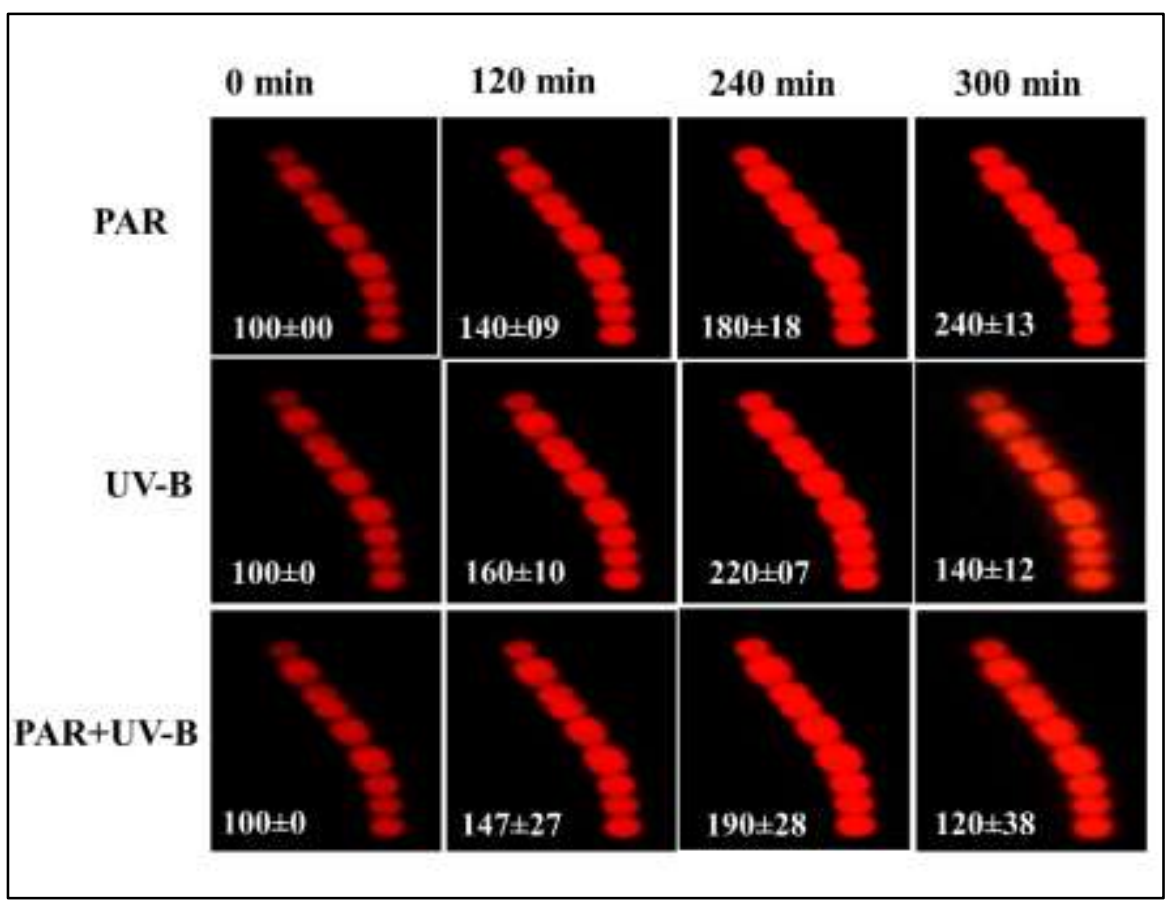

Fig. 6: Fluorescence microscopic images of Nostoc sp. strain HKAR-2 after 0, 120, 240 and $300 \mathrm{~min}$ exposure of PAR, UV-B and PAR+UV-B radiations. Fluorescence percentage is indicated in brackets.

\section{In-Vivo Fluorescence of PBPs}

In-vivo emission fluorescence of PBPs in cyanobacterial cells was visualized after $300 \mathrm{~min}$ of exposure to PAR, UV$\mathrm{B}$, and $\mathrm{PAR}+\mathrm{UV}-\mathrm{B}$ radiations. The internal fluorescence of PBPs had increased up to 2.4 fold after $300 \mathrm{~min}$ of exposure to PAR. However, internal fluorescence of PBPs had increased up to 2.2 and 1.9 fold after $240 \mathrm{~min}$ exposure of UV-B and PAR+UV-B radiations (Fig. 6). Further irradiation of UV-B and PAR+UV-B resulted in a decline in fluorescence after $300 \mathrm{~min}$ of exposure which indicates the photobleaching of cyanobacteria (Kannaujiya and Sinha, 2016c).

\section{Conclusion}

The present work describes the short duration exposure effects of PAR and UV-B radiations on PBPs composition in a hot-spring cyanobacterium Nostoc sp. strain HKAR-2. The absorbance and emission fluorescence intensity of PC and PE indicated a rapid synthesis of PBPs up to $240 \mathrm{~min}$ of exposure to UV-B and PAR+UV-B radiations. This method can be used for the production of PC and PE from cyanobacterial sources for many biotechnological and biomedical applications.

\section{Acknowledgement}

Vinod K. Kannaujiya is thankful to the University Grant Commission (UGC), New Delhi, India, for financial support in the form of a Dr. D.S. Kothari Post-Doctoral Research Grant (F.4-2/2006(BSR)/14-15/0526).

\section{Conflict of Interest}

The authors have no conflicts of interest.

\section{References}

Adir N (2008) Structure of the phycobilisome antennae in cyanobacteria and red algae. In Fromme $\mathrm{P}$ (ed) Photosynthetic Protein Complexes: A Structural Approach. Wiley-VCH Verlag GmbH \& Co. KGaA, Weinheim, Germany, 243-274. DOI: 10.1002/9783527623464.ch11

Ballaré CL, Caldwell MM, Flint SD, Robinson SA, Bornman JF (2011) Effects of solar ultraviolet radiation on terrestrial ecosystems. patterns, mechanisms, and interactions with climate change. Photochem. Photobiol. Sci. 10: 226-241. DOI: $10.1039 / \mathrm{c} 0 \mathrm{pp} 90035 \mathrm{~d}$

Banerjee M, Sinha RP, Häder D-P (1998) Biochemical and spectroscopic changes in phycobiliproteins of the cyanobacterium, Aulosira fertilissima, induced by UV-B radiation. Acta Protozool. 37: 145-148.

Chaiklahan R, Chirasuwan N, Loha V, Tia S, Bunnag B (2011) Separation and purification of phycocyanin from Spirulina sp. using a membrane process. Bioresour. Technol. 102: 7159-7164. DOI: 10.1016/j.biortech.2011.04.067

Fischer WF (2008) Life before the rise of oxygen. Nature 455: 1051-1052. DOI: $10.1038 / 4551051 \mathrm{a}$

Grossman A, Schaefer MR, Chiang GG, Collier JL (1993) The phycobilisomes, a light-harvesting complex responsive to environmental conditions. Microbiol. Rev. 57: 725-749.

Häder D-P, Sinha RP (2005) Solar ultraviolet radiation-induced DNA damage in aquatic organisms: potential environmental impact. Mut. Res. 571: 221-223. DOI: 10.1016/j.mrfmmm.2004.11.017

Häder D-P, Williamson CE, Wängberg S, Rautio M, Rose KC, Gao K, Helbling EW, Sinha RP, Worrest R (2015) Effects 
of UV radiation on aquatic ecosystems and interactions with other environmental factors. Photochem. Photobiol. Sci. 14: 108-126. DOI: 10.1039/C4PP90035A

Kannaujiya VK, Richa, Sinha RP (2014) Peroxide scavenging potential of ultraviolet-B-absorbing mycosporine-like amino acids isolated from a marine red alga Bryocladia sp. Front. Environ. Sci. 2: 1-8.

Kannaujiya VK, Sinha RP (2015) Impacts of varying light regimes on phycobiliproteins of Nostoc sp. HKAR-2 and Nostoc sp. HKAR-11 isolated from diverse habitats. Protoplasma 252: 1551-1561. DOI: 10.1007/s00709-015-0786-5

Kannaujiya VK, Sinha RP (2016a) Thermokinetic stability of phycocyanin and phycoerythrin in food-grade preservatives. J. Appl. Phycol. 28: 1063-1070. DOI: 10.1007/s10811-015-0638-x

Kannaujiya VK, Sinha RP (2016b) An efficient method for separation and purification of phycobiliproteins from ricefield cyanobacterium Nostoc sp. strain HKAR-11. Chromatographia 79: 335-343. DOI: 10.1007/s10337016-3025-0

Kannaujiya VK, Sinha RP (2016c) Impacts of rhythmic alteration of ultraviolet-B and photosynthetic active radiationonphycobiliproteins of hot spring cyanobacterium Nostoc sp. strain HKAR-2. Protoplasma DOI: 10.1007/s00709-016-0964-0

Lao K and Glazer AN (1996) Ultraviolet-B destruction of a light harvesting complex. Proc. Natl. Acad. Sci. USA 93: 52585263. DOI: $10.1073 /$ pnas.93.11.5258

Madronich S, McKenzie RL, Björn LO, Caldwell MM (1998) Changes in biologically active ultraviolet radiation reaching the Earth's surface. J. Photochem. Photobiol. B: Biol. 46: 5-19. DOI: 10.1016/S1011-1344(98)00182-1

Olsson-Francis K, Watson JS, Cockell CS (2013) Cyanobacteria isolated from the high-intertidal zone: a model for studying the physiological prerequisites for survival in low Earth orbit. Int. J. Astrobiol. 12: 292-303. DOI: 10.1017/S1473550413000104

Polo LK, de Marthiellen LFR, Kreusch M, Pereira DT, Costa GB, Simioni C, Ouriques LC, Chow F, Ramlov F, Maraschin M, Bouzon ZL, Schmidt EC (2014) Photo acclimation responses of the brown macroalga Sargassum cymosum to the combined influence of UV radiation and salinity: cytochemical and ultrastructural organization and photosynthetic performance. Photochem. Photobiol. 90: 560-573. DOI: $10.1111 /$ php.12224

Pumas C, Vacharapiyasophon P, Peerapornpisal Y, Leelapornpisid P, Boonchum W, Ishii M. Khanongnuch C (2011) Thermostablility of phycobiliproteins and antioxidant activity from four thermotolerant cyanobacteria. Phycol. Res. 59: 166-174. DOI: 10.1111/j.1440-1835.2011.00615.x

Rastogi RP, Incharoensakdi A, Madamwar D (2014) Responses of a rice-field cyanobacterium Anabaena siamensis TISTR8012 upon exposure to PAR and UV radiation. J. Plant Physiol. 171: 1545-1553. DOI: 10.1016/j.jplph.2014.07.011
Rastogi RP, Kumari S, Richa, Han T, Sinha RP (2012) Molecular characterization of hot spring cyanobacteria and evaluation of their photoprotective compound. Can. J. Microbiol. 58: 719-727. DOI: 10.1139/w2012-044

Rastogi RP, Singh SP, Häder D-P, Sinha RP (2011) Ultraviolet-Binduced DNA damage and photorepair in the cyanobacterium Anabaena variabilis PCC 7937. Env. Exp. Bot. 74: 280-288. DOI: 10.1016/j.envexpbot.2011.06.010

Richa, Kannaujiya VK, Kesheri M, Singh G, Sinha RP (2011) Biotechnological potentials of phycobiliproteins. Int. J. Pharma Bio Sci. 2: B446-454.

Rippka R, Deruelles J, Waterbury JB, Herdman M, Stanier RY (1979) Generic assignments,strain histories and properties of pure cultures of cyanobacteria. J. Gen. Microbiol. 111: 1-61. DOI: 10.1099/00221287-111-1-1

Roger PA, Kulasooriya SA (1980) Blue-Green Algae and Rice. The International Rice Research Institute, Los Baňos, Philippines.

Santos AL, Moreirinha C, Lopes D, Esteves AC, Henriques I, Almeida A, Domingues MRM, Delgadillo I, Correia A, Cunha Ä (2013) Effects of UV Radiation on the Lipids and Proteins of Bacteria Studied by Mid-Infrared Spectroscopy. Environ. Sci. Technol. 47: 6306-6315. DOI: $10.1021 / \mathrm{es} 400660 \mathrm{~g}$

Sinha RP, Häder D-P (1996) Photobiology and ecophysiology of rice field cyanobacteria. Photochem. Photobiol. 64: 887896. DOI: 10.1111/j.1751-1097.1996.tb01852.x

Sinha RP, Häder D-P (2003) Biochemistry of phycobilisomes disassembly by ultraviolate-B radiation in cyanobacteria. Recent Res. Devel. Biochem. 4: 945-955.

Sinha RP, Klisch M, Gröniger A, Häder D-P (2001) Responses of aquatic algae and cyanobacteria to solar UV-B. Plant Ecol. 154: 221-236. DOI: 10.1023/A:1012986500543

Sinha RP, Kumari S, Rastogi RP (2008) Impacts of ultraviolet-B radiation on cyanobacteria: photoprotection and repair. $J$. Sci. Res. 52: 125-142.

Sinha RP, Lebert M, Kumar A, Kumar HD, Häder D-P (1995a) Spectroscopic and biochemical analyses of UV effects of phycobilisomes of Anabaena sp. and Nostoc carmium. Bot. Acta 108: 87-92. DOI: 10.1111/j.14388677.1995.tb00836.x

Sinha RP, Lebert M, Kumar A, Kumar HD, Häder D-P (1995b) Disintegration of phycobilisomes in a rice field cyanobacterium Nostoc sp. following UV irradiation. Biochem. Mol. Biol. Int. 37: 697-706.

Sinha RP, Richter P, Faddoul J, Braun M, Häder D-P (2002) Effects of UV and visible light on cyanobacteria at the cellular level. Photochem. Photobiol. Sci. 1: 553-559. DOI: 10.1039/B203955A

Sinha RP, Singh N, Kumar A, Kumar HD, Häder M, Häder D-P (1996) Effects of UV irradiation on certain physiological and biochemical processes in cyanobacteria. $J$. Photochem. Photobiol. B: Biol. 32: 107-113. DOI: 10.1016/1011-1344(95)07205-5 
Stanier RY, Cohen-Bazire G (1977) Phototrophic prokaryotes: the cyanobacteria. Ann. Rev. Microbiol. 31: 225-274. DOI: 10.1146/annurev.mi.31.100177.001301

Stock CA, Dunne JP, John JG (2014) Global-scale carbon and energy flows through the marine planktonic food web: an analysis with a coupled physical-biological model. Prog.
Oceanogr.

120:

$1-28$.

DOI:

10.1016/j.pocean.2013.07.001

Tandean de Marsac N and Cohen-Bazzire G (1977) Molecular composition of cyanobacterial phycobilisomes. Proc. Natl. Acad. Sci. USA 74: 1635-1639. DOI: 10.1073/pnas.74.4.1635 